\title{
A Greener Enzymatic Oligoesterification of Biobased Renewable Synthons
}

\author{
Juan Villavicencio, ${ }^{\oplus a}$ Ferley Orozco, ${ }^{\oplus b}$ Ricardo Benitez, ${ }^{\oplus a}$ Jaime Martin ${ }^{\circledR *, a}$ and \\ Giovanni Rojas ${ }^{\circledR *}, b$ \\ ${ }^{a}$ Grupo de Investigación Química de Productos Naturales, Universidad del Cauca, 190003 Popayán, Colombia \\ ${ }^{b}$ Grupo Natura, Departamento de Ciencias Químicas, Universidad Icesi, 760031 Cali, Colombia
}

\begin{abstract}
Polyesters of xylitol and succinic acid were prepared yielding from 70 to $75 \%$ by enzymecatalyzed esterification using a molar mass from $1: 1$ to $2: 5$ at 120 and $140{ }^{\circ} \mathrm{C}$ employing from 1 to $10 \% \mathrm{~m} / \mathrm{m}$ of enzyme. Control over branching degree was achieved by tuning the reaction conditions (temperature, time, comonomer ratio, enzyme content). This one-step process from renewable starting materials avoids protection-deprotection techniques, as well as the use of toxic solvents by introducing limonene as solvent for polyesterification for the first time. All materials were structurally characterized by infrared (IR) and nuclear magnetic resonance (NMR) spectroscopy, their thermal properties were studied by differential scanning calorimetry (DSC) and thermogravimetric analysis (TGA), and the molecular weight of samples were obtained by gel-permeation chromatography (GPC).
\end{abstract}

Keywords: enzymatic polymerization, Novozym ${ }^{\circledR}-435$, biomaterials, green chemistry, limonene

\section{Introduction}

Polymer science and polymer production have played important roles in modern life. However, consumers and producers are becoming increasingly conscious of plastic waste accumulation of petroleum-derived plastics, mostly used in short-term applications. ${ }^{1-4}$ Currently, polymer scientists are investigating methods to replace non-degradable materials with biodegradable or compostable feedstocks. ${ }^{5-9}$ For example, xylitol can be obtained from sugarcane bagasse, a byproduct from the sugarcane industry: ${ }^{10}$ by extraction of xylan, followed by conversion into xylose via hydrolysis, and then to xylitol by hydrogenation or bioconversion. ${ }^{11}$ However, xylitol can be produced directly from bagasse by fermentation with the yeast Debaryomyces hansenii..$^{12}$ Although mainly used as a sugar substitute because its metabolism is not insulinregulated ${ }^{13}$ xylitol has been listed by the U.S Department of Energy as one of the potential building blocks of the future. ${ }^{14}$ Unfortunately, its production is not yet massively exploited. ${ }^{15}$ Xylitol-based polyesters are attractive because of their polyfunctional nature, which allows molecules to be introduced in the polymer backbone with little effort compared to the use of classical diol monomers. ${ }^{16,17}$ Polyesters with polyol or polyacid repeat units can be

*e-mail: jmartinf@unicauca.edu.co; grojas@icesi.edu.co prepared by chemical methods yielding in some cases hyperbranched or even crosslinked polymers. ${ }^{11,18}$ Chemical routes to linear polyesters from polyols require complex synthetic protection-deprotection steps. In any case, polyesters require expensive processes involving high temperature, usually above $150^{\circ} \mathrm{C}$.

A promising greener approach is the use of enzymes for polymerization. ${ }^{19-24}$ Lipases are known for regioselective esterification of low molar mass substrates at temperatures from 30 to $70{ }^{\circ} \mathrm{C} .{ }^{25}$ However, only a few studies have reported enzymatic polymerization of xylitol. ${ }^{26}$ For example, Hu et al. ${ }^{27}$ reported the polyesterification of xylitol and adipic acid using the lipase Novozym ${ }^{\circledR} 435$ at $90^{\circ} \mathrm{C}$ for $46 \mathrm{~h}$, yielding low molecular weight polymers. Succinic acid has been used in polymer science as substrate for enzymatic polymerizations. The most important succinic acid-based polymer is polybutylene succinate (PBS) which has proved to be a promising material for biomedical applications. Several modifications and copolymerizations have been developed for PBS-based materials to improve their mechanical properties. ${ }^{28}$ Furthermore, dicarboxylic acids such as succinic acid have been used for "green crosslinking" of carbohydrate polymers. The resulting materials exhibited enhanced physical properties with very promising applications for tissue engineering due to their integration of biological monomers and their metal-free catalyzed synthesis. $^{28}$ 
In this work, we report the production of polyesters based on xylitol (XYL) and succinic acid (SUC) as comonomers and catalyzed by immobilized Candida antarctica lipase B $\left(\right.$ Novozym $^{\circledR} 435$ ) (CALB). ${ }^{28,29}$ The simple synthetic strategy does not require protection-deprotection reactions and yields oligomeric materials (OXS), instead of hyperbranched or crosslinked polymers. Additionally, and more importantly, the reaction was carried out in limonene as a green solvent. Although limonene has been used as solvent in industry, ${ }^{30,31}$ this is the first report that employs limonene as solvent for green polyesterification, making this methodology environmentally friendly. ${ }^{32}$

\section{Experimental}

\section{Chemicals}

Xylitol and succinic acid ( $\geq 99 \%$ purity) were purchased from Sigma-Aldrich, Saint Louis, MO, USA; Novozym ${ }^{\circledR}$ 435 Candida antarctica lipase B (CALB) immobilized on macroporous acrylic resin was donated by Novozymes Brazil (Barigui, Araucária, PR, Brazil). Industrial grade limonene was supplied from a local distributor, Quimtia Colombia SAS (Cali, Colombia).

\section{Chemical synthesis of oligomers}

The oligomers were obtained in a reflux setup by enzymatic synthesis from succinic acid and xylitol in a XYL:SUC molar ratio of 1:1 for OXSB and 2:5 for OXSA. Products were named with the prefix OXS for oligomers of xylitol and succinic acid, and the suffix A or B for the respective molar ratio (Table 1). Each xylitol and succinic acid mixture (7.4 mmol of XYL and SUC for OXSB and $4.5 \mathrm{mmol}$ of XYL and $11.25 \mathrm{mmol}$ of SUC for OXSA) were solubilized in a $50 \mathrm{~mL}$ round-bottom flask in the presence of $10 \mathrm{~mL}$ of limonene. For both OXSA and OXSB, CALB was added to the reaction flask and stirred at room temperature for $1 \mathrm{~h}$. The amount of CALB added to the reaction was 1 and $10 \% \mathrm{~m} / \mathrm{m}$ for OXSA and OXSB, respectively. Final mixtures were heated at $120{ }^{\circ} \mathrm{C}(\mathrm{OXSA})$ and $140{ }^{\circ} \mathrm{C}$
(OXSB) during 48 and $30 \mathrm{~h}$, respectively. The products were solubilized in $1 \mathrm{~mL}$ of water and then precipitated in $1 \mathrm{~L}$ of cold ethyl acetate. The resulting oligomers were filtered and reprecipitated. The materials were dried in an oven at $90{ }^{\circ} \mathrm{C}$ for at least two days.

\section{General methods}

Fourier transform infrared (FTIR) spectroscopy was performed using a Nicolet iS10 FT-IR spectrometer in the attenuated total reflection (ATR) mode, Thermo Fisher Scientific (Waltham, MA, USA).

Nuclear magnetic resonance spectra $\left({ }^{1} \mathrm{H}\right.$ and ${ }^{13} \mathrm{C}$ NMR) were recorded in $\mathrm{D}_{2} \mathrm{O}$ using a Bruker instrument (Billerica, MA, United States) at $400 \mathrm{MHz}$ for protons. Chemical shifts were reported in ppm relative to $\mathrm{D}_{2} \mathrm{O}(4.82 \mathrm{ppm})$ with tetramethylsilane as internal reference. Thermal transitions and stability were determined by differential scanning calorimetry (DSC Q2000 V24.11), TA instruments (New Castle, DE, USA) and thermogravimetric analysis (TGA Q50 V20.10) from TA instruments (New Castle, DE, USA). DSC analysis was performed using an instrument equipped with a controlled cooling accessory at a heating rate of $10{ }^{\circ} \mathrm{C} \mathrm{min}{ }^{-1}$. Calibrations were made using indium and freshly distilled $n$-octane as the standards for peak temperature transitions and indium for the enthalpy standard. All samples were prepared in hermetically sealed pans (5-10 mg per sample) and were run using an empty pan as a reference and empty cells as a subtracted baseline. The samples were scanned for multiple cycles to remove recrystallization differences between the samples, and the results reported are of the third scan in the cycle. TGA was performed for all samples heated from room temperature to $800{ }^{\circ} \mathrm{C}$ in nitrogen at a scan rate of $10^{\circ} \mathrm{C} \mathrm{min}^{-1}$. The onset of weight loss was taken as the initial degradation temperature.

Molecular weights were evaluated by gel-permeation chromatography (GPC) at $30^{\circ} \mathrm{C}$ using a HPLC Agilent 1260 (Santa Clara, CA, USA) equipped with C Shodex OHPak SB-805 $(8.0 \times 300 \mathrm{~mm}, 13 \mu \mathrm{m})$ and Shodex OHPak SB$806(8.0 \times 300 \mathrm{~mm}, 13 \mu \mathrm{m})$ columns and a refractive index detector.

Table 1. Reaction conditions and results for the synthesized products

\begin{tabular}{|c|c|c|c|c|c|c|c|c|c|c|c|}
\hline Oligomer & time $/ \mathrm{h}$ & $\begin{array}{c}\text { Temperature / } \\
{ }^{\circ} \mathrm{C}\end{array}$ & CALB / \% & $\begin{array}{l}\text { Monomer } \\
\text { molar ratio }\end{array}$ & $\begin{array}{c}\mathrm{Mw} / \\
\left(\mathrm{g} \mathrm{mol}^{-1}\right)\end{array}$ & $Đ$ & $\mathrm{~T}_{\mathrm{g}} /{ }^{\circ} \mathrm{C}$ & $\begin{array}{c}\Delta \mathrm{Cp} / \\
\left(\mathrm{J} \mathrm{g}^{-1}{ }^{\circ} \mathrm{C}^{-1}\right)\end{array}$ & $\mathrm{T}_{\text {onset }} /{ }^{\circ} \mathrm{C}$ & $\mathrm{T}_{\text {peak }} /{ }^{\circ} \mathrm{C}$ & Yield / \% \\
\hline OXSA & 48 & 120 & 1 & $2: 5$ & 1520 & 1.61 & $\begin{array}{l}-7 \\
10\end{array}$ & $\begin{array}{l}0.26 \\
0.10\end{array}$ & 257 & 359 & 70 \\
\hline OXSB & 30 & 140 & 10 & $1: 1$ & 1776 & 1.32 & $\begin{array}{c}9 \\
24\end{array}$ & $\begin{array}{l}0.40 \\
0.19\end{array}$ & 252 & 368 & 75 \\
\hline
\end{tabular}

aMonomer ratio XYL:SUC. CALB: Candida antarctica lipase B (Novozym 435) m/m; Mw: molecular weight; Đ: dispersity; $\mathrm{T}_{\mathrm{g}}$ : glass transition temperature; $\Delta \mathrm{Cp}$ : heat capacity; $\mathrm{T}_{\text {onset }}$ : onset temperature; $\mathrm{T}_{\text {peak }}$ : peak temperature. 


\section{Results and Discussion}

Different substrates from renewable sources have been used to synthesize polyesters via enzymatic and traditional chemistry, yielding materials having chemical properties according to their morphologies (crosslinked, branched or linear). ${ }^{18,25,27,28,33}$ In this work, as shown in Figure 1, it was possible to achieve chemical control over the reactivity of the hydroxyl groups from xylitol towards succinic acid using CALB as a catalyst, which produced oligomers with defined morphologies instead of hyperbranched or crosslinked materials.

Two type of materials were obtained from the enzymatic esterification of XYL with SUC. Table 1 shows the oligomers synthesized at different temperatures (120 and $140{ }^{\circ} \mathrm{C}$ ), reaction times $(30$ and $48 \mathrm{~h}$ ), monomer ratio (1:1 and 2:5) and percentage of enzyme (1 and 10\%). All materials were structurally characterized by FTIR and NMR; the molecular weights of oligomers were measured by GPC, and the thermal behaviors were determined using DSC and TGA.

Attenuated total reflectance Fourier transform infrared (ATR-FTIR) spectroscopy was used to follow the reaction progress. Figure 2 a shows the direct comparison of pure monomers and the resultant oligomer OXSB. Stretching vibrations from the starting materials (around $3300 \mathrm{~cm}^{-1}$ for the hydroxyl groups in XYL and $1700 \mathrm{~cm}^{-1}$ for the carbonyl group in SUC) disappeared, while new vibrations from the polyesterification product appeared around 3381 and $1721 \mathrm{~cm}^{-1}$, corresponding to the oligomer hydroxyl groups and the carbonyl from the ester linkage, respectively. Additionally, OXSB showed a new stretching vibration around $1160 \mathrm{~cm}^{-1}$ from $\mathrm{C}-\mathrm{O}$, which confirms the successful formation of the oligomer. Figure $2 b$ shows the IR spectra of both oligomeric materials, OXSA and OXSB, which were obtained by varying the reaction time, temperature, percentage of enzyme and monomer ratio. Around $3381 \mathrm{~cm}^{-1}$ an increase in the band intensity from the $\mathrm{O}-\mathrm{H}$ for OXSB is shown, which suggests that there are more available hydroxyl groups in OXSB than in OXSA. This trend is in agreement with the increment of band intensity at 877 and $1381 \mathrm{~cm}^{-1}$ from the $\mathrm{C}-\mathrm{O}$ bonds in OXSB, which shows that more ester groups are formed than in OXSA. It is important to highlight that for OXSB an excess of CALB and SUC were used with the intention of forming a hyperbranched polymer. However, a significant decrease in the $\mathrm{O}-\mathrm{H}$ band in IR was observed, which suggests that the regioselectivity of CALB in polyols with a stereochemical configuration $[S]-[R]$ as XYL in hydroxyl groups is favored for linear materials. It is possible that the reaction time is also a key factor (see Table 1) in OXSA and OXSB topologies, in agreement with existing studies where racemization increases with the time of synthesis. ${ }^{27}$

In addition to the infrared study, NMR characterization by ${ }^{1} \mathrm{H}$ NMR, ${ }^{13} \mathrm{C}$ NMR and DEPT135 (distortionless enhancement of polarization transfer) confirmed formation of the desired products. Figure 3 shows the NMR spectra and the assignment for each signal for OXSB (NMR data for OXSA is available in the Supplementary Information section). Figure 3 a shows the ${ }^{1} \mathrm{H}$ NMR, where the chemical
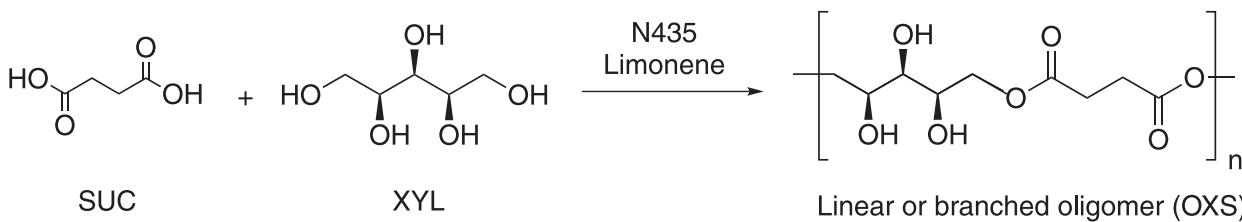

Linear or branched oligomer (OXS)

Figure 1. Enzymatic reaction of SUC and XYL.

(a)

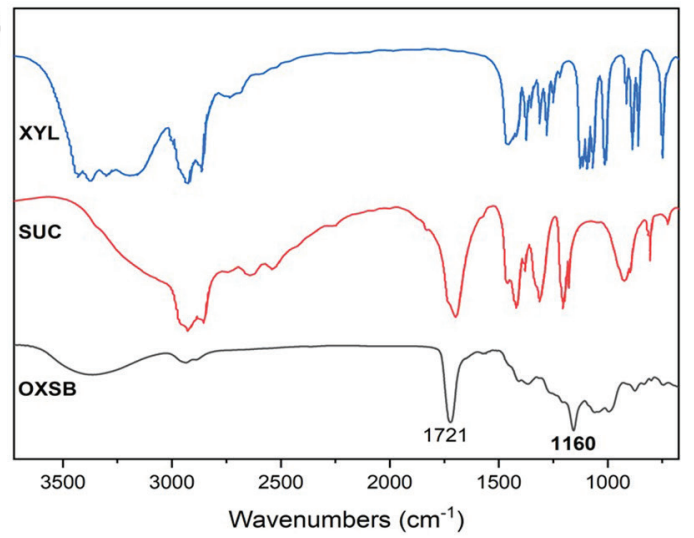

(b)

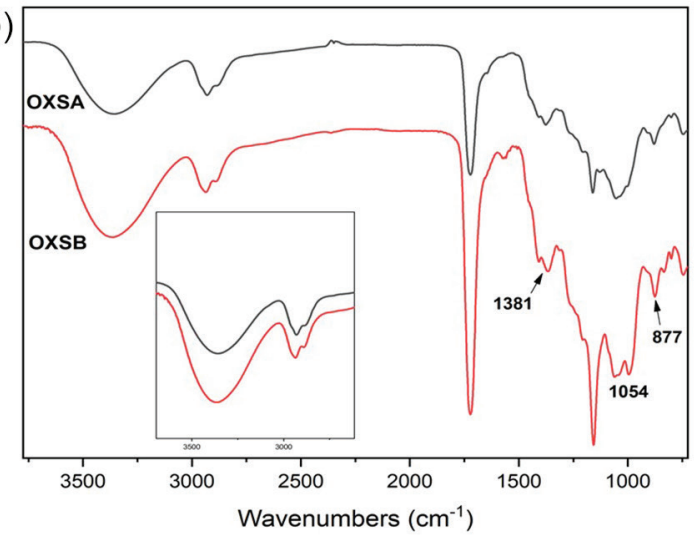

Figure 2. (a) ATR-FTIR of oligomer and monomers; (b) ATR-IR spectra of synthesized oligomers. 
shifts from 3.5 to $4.5 \mathrm{ppm}$, marked as signals b, c, d and $\mathrm{e}$, belong to hydrogens from the xylitol moiety in the oligomer. The signal a marked at $2.75 \mathrm{ppm}$ corresponds to $\mathrm{CH}_{2}$ from the succinic acid moiety after formation of the respective polyester. The signals from NMR, along with the IR data, confirm the successful esterification of the $\mathrm{O}-\mathrm{H}$ primary groups from XYL and the carboxylic acid groups from SUC. More importantly, possible control over branching using a simple enzymatic step without additional processing is indicated. Figure $3 \mathrm{~b}$ shows the ${ }^{13} \mathrm{C}$ NMR and DEPT135 for OXSB. While signals marked as a and $\mathrm{f}$ at 31.36 and $177 \mathrm{ppm}$ belong to methylenes and carbonyl groups from the succinic acid moiety, respectively, and signals b, c, d and e from 60 to $80 \mathrm{ppm}$ belong to the carbons from the xylitol moiety in the oligoester. The DEPT135 spectrum shows several negative signals, which correspond to methylenes a from the succinic acid moiety and $b, c$ from the xylitol polyester moiety.
The IR and NMR spectra provided information about the primary structure of the synthesized oligomers, while their thermal behavior was additionally studied by DSC and TGA, as shown in Figure 4. For both materials, low glass transition temperature $\left(\mathrm{T}_{\mathrm{g}}\right)$ and and heat capacity $(\Delta \mathrm{Cp})$ were observed, which is consistent with the presence of oligomers instead of long-chain polymers. While both materials were apparently similar in terms of consistency, viscosity, color, and solubility, OXSA and OXSB showed very different thermal behavior. While OXSA was synthesized at $120^{\circ} \mathrm{C}$, employing an excess of SUC for a longer reaction time, $48 \mathrm{~h}, \mathrm{OXSB}$ was obtained after $30 \mathrm{~h}$ of reaction with an equimolar content of monomers at $140^{\circ} \mathrm{C}$, which consequently produced two different materials. OXSA shows two glass transitions at -7 and $10{ }^{\circ} \mathrm{C}$ with $\Delta \mathrm{Cp}$ of 0.26 and $0.10 \mathrm{~J} \mathrm{~g}^{-1}{ }^{\circ} \mathrm{C}^{-1}$, respectively, while OXSB show two glass transitions at 9 and $24{ }^{\circ} \mathrm{C}$ with $\Delta \mathrm{Cp}$ of 0.40 and $0.19 \mathrm{~J} \mathrm{~g}^{-1}{ }^{\circ} \mathrm{C}^{-1}$, respectively.

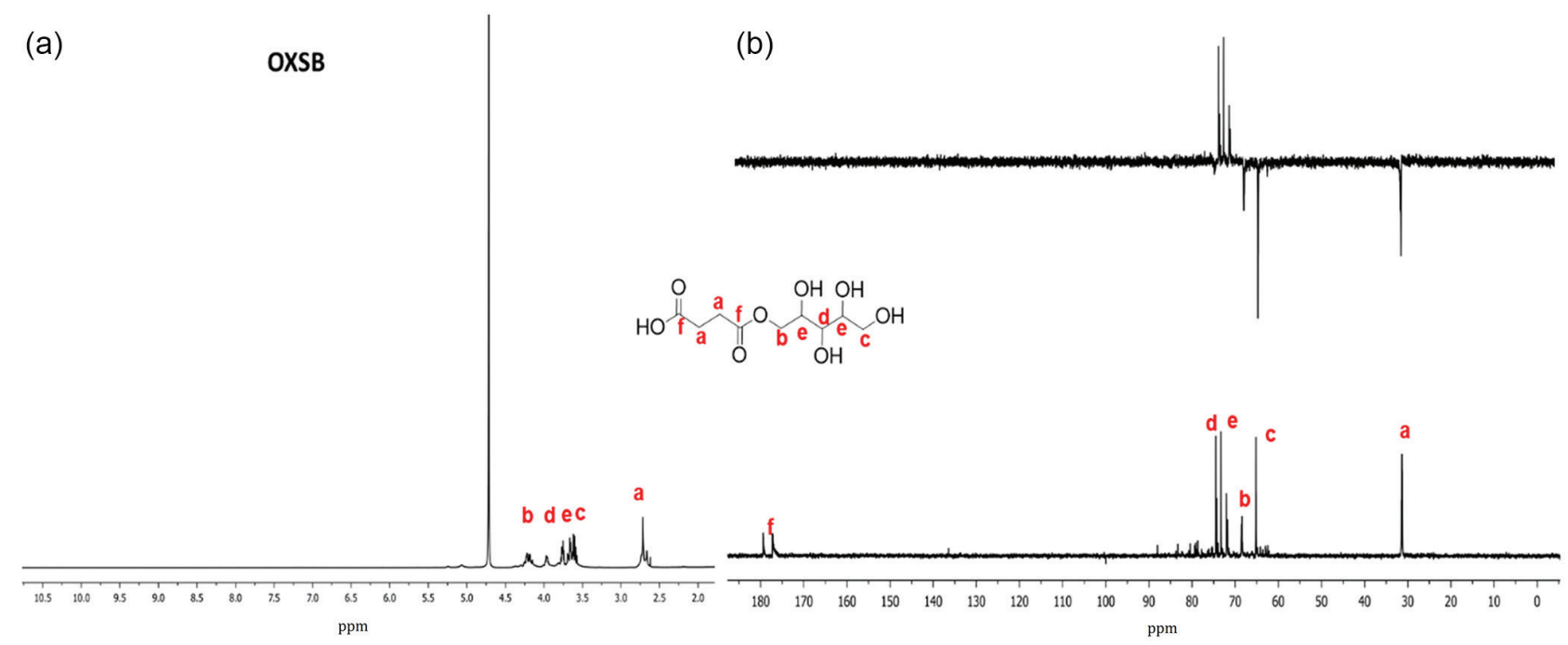

Figure 3. (a) ${ }^{1} \mathrm{H}$ NMR spectra $\left(400 \mathrm{MHz}, \mathrm{D}_{2} \mathrm{O}\right)$ for the synthesized OXSB oligomer; (b) NMR (100 MHz, $\left.\mathrm{D}_{2} \mathrm{O}\right)$ spectra for the synthesized OXSB oligomer, top: DEPT 135 , bottom: ${ }^{13} \mathrm{C}$.
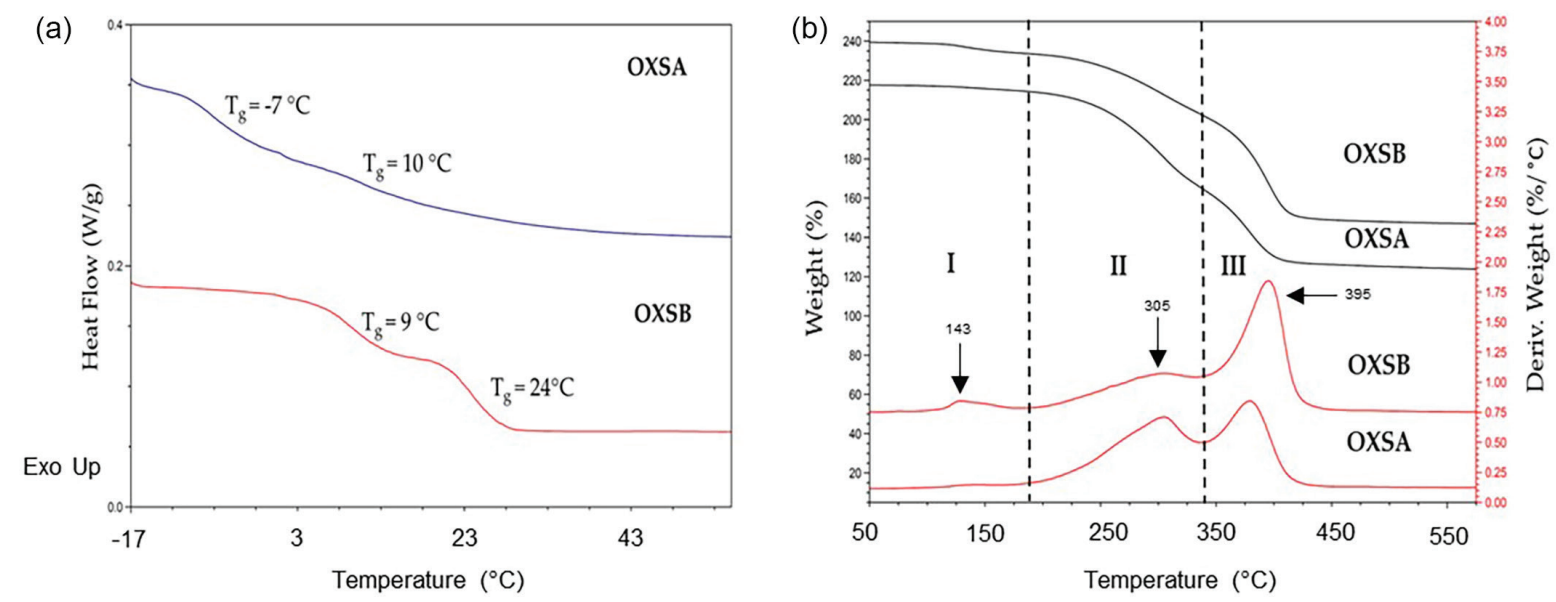

Figure 4. (a) DSC for oligomers synthesized; (b) TGA and DTG for materials obtained. 
<smiles>COC[C@H](O)[C@@H](O)[C@H](O)COC</smiles>

1<smiles>COC[C@H](O)[C@@H](OC)[C@@H](O)CO</smiles>

4<smiles>COC[C@H](OC)[C@@H](O)[C@H](O)CO</smiles><smiles>COCC(OC)C(O)C(CO)OC</smiles><smiles>COC[C@H](O)[C@@H](O)[C@H](CO)OC</smiles>

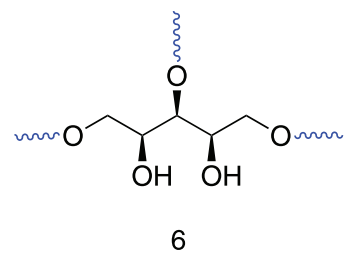

Figure 5. Possible substitution patterns for the XYL backbone with SUC. Structures 1 to 4 belong to OXSB and structures 5 and 6 belong to OXSA.

Thermal stability of the materials was analyzed by TGA and first derivative thermogravimetric analysis (DTG), as shown in Figure 4. Both materials present similar thermal stability by TGA; however, from DTG it is possible to observe some differences. OXSA is more stable with mass loss starting at $143{ }^{\circ} \mathrm{C}$, while OXSB shows the first mass loss at $129^{\circ} \mathrm{C}$, which is depicted in Figure $4 \mathrm{~b}$ in zone I. Although both materials showed mass loss in the area marked zone II, at $305{ }^{\circ} \mathrm{C}$ the mass loss for OXSA was larger than that for OXSB, suggesting that OXSB is more stable than OXSA at higher temperatures. Zone III at $395^{\circ} \mathrm{C}$ shows the final and most significant decomposition for both materials, showing that the mass loss is greater for OXSB than OXSA, which suggests that OXSB is the most thermally stable of the two oligomers.

This behavior is related to the molecular weight and the dispersity obtained by GPC, as well as the change on $\mathrm{T}_{\mathrm{g}}$ observed when increasing the temperature from 120 to $140{ }^{\circ} \mathrm{C}$. Table 1 shows that OXSB presents a slightly higher number-average molecular weight and lower dispersity (Đ) than OXSA, suggesting that there may primarily be one decomposition for OXSB with more homogeneous chain size. In contrast, OXSA is less thermally stable since it presents mass loss from smaller molecules at lower temperatures, because of a less uniform chain size distribution, with less linear and more polydisperse chains.

Since both materials are short chain molecules and the presence of two $\mathrm{T}_{\mathrm{g}}$ for each oligomer confirms the existence of independent thermic transitions among their respective chains, it is proposed that "pseudo fusions" are present. This term describes random topologies leading to dissimilar physical properties in specific regions. Linear more organized structures were expected, because of polyesterification only on the primary alcohols for OXSB as observed in the IR. However, the pseudo fusion was more pronounced in OXSB than in OXSA. This tendency could be explained through the random substitution of $\mathrm{OH}$ groups from the XYL backbone by SUC molecules, yielding for
OXSB linear oligomers from similar reactivities in all of the hydroxyl groups from XYL, as shown in Figure 5, structures 1 to 4 . On the other hand, OXSA presented less organized and branched structures with lower $T_{g}$ than OXSB; Figure 5, structures $\mathbf{5}$ and $\mathbf{6}$ show two possible xylitol linkage options yielding branched materials. The previous behavior could be explained by the catalytic action of the enzyme, which prefers to react mainly with primary alcohols yielding more linear polymers at shorter reaction times, after prolonged reaction times branching or crosslinked polymers could be formed.

\section{Conclusions}

A series of oligomeric materials was obtained yielding from 70 to $75 \%$ of pure products by enzymatic polyesterification while controlling time and temperature. This simple and greener methodology using renewable substrates produces oligomers from xylitol and succinic acid using for the first time limonene as solvent for polymerization. The proposed methodology allows production of oligomers with diverse branching degrees from almost linear to branched materials by simply controlling the reaction parameters, such as temperature and reaction time, and more importantly avoiding the use of protection-deprotection processes.

\section{Supplementary Information}

Supplementary data ( ${ }^{1} \mathrm{H}$ NMR, DEPT- 135 and $\left.{ }^{13} \mathrm{CNMR}\right)$ are available free of charge at http://jbcs.sbq.org.br as PDF file.

\section{Acknowledgments}

The authors express gratitude to Quimtia Colombia SAS and Novozymes Latin América Ltda. for providing the enzyme Novozym ${ }^{\circledR} 435$. Also, we would like to thank 
Universidad del Cauca (501100005682) under grant ID 4664 and the Laboratorio de Instrumentación Química (LIQ) at Universidad Icesi for analytical support. Special thanks to Dr Kathryn Williams at University of Florida for helping with the preparation of the manuscript.

\section{References}

1. Vegter, A. C.; Barletta, M.; Beck, C.; Borrero, J.; Burton, H.; Campbell, M. L.; Costa, M. F.; Eriksen, M.; Eriksson, C.; Estrades, A.; Endangered Species Res. 2014, 25, 225.

2. Tsai, C.-J.; Chen, M.-L.; Chang, K.-F.; Chang, F.-K.; Mao, I.-F.; Chemosphere 2009, 74, 1104.

3. Blettler, M. C. M.; Ulla, M. A.; Rabuffetti, A. P.; Garello, N.; Environ. Monit. Assess. 2017, 189, 581.

4. Wilcox, C.; van Sebille, E.; Hardesty, B. D.; Proc. Natl. Acad. Sci. U.S.A. 2015, 112, 11899.

5. Kasetaite, S.; Ostrauskaite, J.; Grazuleviciene, V.; Bridziuviene, D.; Budreckiene, R.; Rainosalo, E.; React. Funct. Polym. 2018, 122,42 .

6. Narayan, R. In Opportunities for Innovation (Biotechnology); NIST GCR 93-633; National Institute for Standards and Technology: Gaithersburg, MD, 1993.

7. Mano, J. F.; Sousa, R. A.; Boesel, L. F.; Neves, N. M.; Reis, R. L.; Compos. Sci. Technol. 2004, 64, 789.

8. Chanprateep, S.; J. Biosci. Bioeng. 2010, 110, 621.

9. Jain, P.; Jain, A.; Singhai, R.; Jain, S.; Int. J. Life Sci. 2017, 1, 58.

10. Moncada, J.; Matallana, L. G.; Cardona, C. A.; Ind. Eng. Chem. Res. 2013, 52, 4132.

11. Liz-Andela, N. I.; Benitez, R.; Martin-Franco, J.; Rojas, G.; Polym. Int. 2017, 66, 532.

12. Prakash, G.; Varma, A. J.; Prabhune, A.; Shouche, Y.; Rao, M.; Bioresour. Technol. 2011, 102, 3304.

13. Cheng, K. K.; Zhang, J. A.; Ling, H. Z.; Ping, W. X.; Huang, W.; Ge, J. P.; Xu, J. M.; Biochem. Eng. J. 2009, 43, 203.

14. Werpy, T. A.; Petersen, G.; Aden, A.; Bozell, J.; Holladay, J. E.; White, J. F.; Manheim, A.; Elliot, D.; Lasure, L.; Jones, S.; Gerber, M.; Ibsen, K.; Lumberg, L.; Kelley, S.; Top Value Added Chemicals from Biomass: Results of Screening for Potential Candidates from Sugars and Synthesis Gas, No. PNNL-14808, vol. 1; Pacific Northwest National Lab (PNNL): Richland, WA, USA, 2004.
15. Pachapur, V. L.; Sarma, S. J.; Brar, S. K.; Chaabouni, E. In Platform Chemical Biorefinery; Elsevier: Amsterdam, Netherlands, 2016, ch. 2.

16. Bruggeman, J. P.; Bettinger, C. J.; Langer, R.; J. Biomed. Mater. Res., Part A 2010, 95A, 92.

17. Steinbüchel, A.; J. Macromol. Sci., Part A: Pure Appl. Chem. 1995, 32, 653.

18. Orozco, F.; Andrade, A.; Delgado, L. M.; Rojas, G.; Polym. Int. 2020, 69, 577.

19. Debuissy, T.; Pollet, E.; Avérous, L.; Biomacromolecules 2016, 17, 4054.

20. Shoda, S.; Uyama, H.; Kadokawa, J.; Kimura, S.; Kobayashi, S.; Chem. Rev. 2016, 116, 2307.

21. Angajala, G.; Pavan, P.; Subashini, R.; Biocatal. Agric. Biotechnol. 2016, 7, 257.

22. Nie, W.-C.; Dang, H.-C.; Wang, X.-L.; Song, F.; Wang, Y.-Z.; Polymer 2017, 111, 107.

23. Gross, R.; Kalra, B.; Kumar, A.; Appl. Microbiol. Biotechnol. 2001, 55, 655 .

24. Ajima, A.; Yoshimoto, T.; Takahashi, K.; Tamaura, Y.; Saito, Y.; Inada, Y.; Biotechnol. Lett. 1985, 7, 303.

25. Villavicencio Romero, J. D.; Enriquez Fernández, L. E.; Benitez Benitez, R.; Franco, J. M.; Rojas, G.; Rev. Colomb. Biotecnol. 2019, 21, 98 .

26. Bilal, M. H.; Prehm, M.; Njau, A. E.; Samiullah, M. H.; Meister, A.; Kressler, J.; Polymers 2016, 8, 80.

27. Hu, J.; Gao, W.; Kulshrestha, A.; Gross, R. A.; ACS Symp. Ser. 2008, 999, 275.

28. Azim, H.; Dekhterman, A.; Jiang, Z.; Gross, R. A.; Biomacromolecules 2006, 7, 3093.

29. Salihu, A.; Alam, M. Z.; Process Biochem. 2015, 50, 86.

30. Aissou, M.; Chemat-Djenni, Z.; Yara-Varón, E.; Fabiano-Tixier, A.-S.; Chemat, F.; C. R. Chim. 2017, 20, 346.

31. Ciriminna, R.; Lomeli-Rodriguez, M.; Cara, P. D.; LopezSanchez, J. A.; Pagliaro, M.; Chem. Commun. 2014, 50, 15288.

32. Kobayashi, S.; Struct. Chem. 2017, 28, 461.

33. Zhu, Y.; Romain, C.; Williams, C. K.; Nature 2016, 540, 354.

Submitted: December 11, 2020

Published online: February 19, 2021 